\title{
SAĞLIK SEKTÖRÜNDE YALIN FELSEFE
}

Lean Philisophy in The Health Sector

Nezire Zeynep Taşdemir ${ }^{1}$, Fatih Yapıc ${ }^{2}$, Hasan Baş ${ }^{3}$, Ahad Furvgi ${ }^{4}$

\section{ÖZET}

Küreselleşme ile artan rekabet ortaminda mevcudiyetini devam ettirmek isteyen işletmeler mevcut kaynakların en etkin bir şekilde kullanarak verimliliğini artırmak zorundadır. Hem üretim hem de hizmet sektöründe müşsteri talep ve çeşitliliğin artması beraberinde bazı karmaşayı getirmiştir. Bu karmaşayı engelleyebilmek için birçok yaklaşım ve yöntem geliştirilmiş olup, bunlardan en önemlisi hiç kuşkusuz yalın felsefedir. Yalın felsefeyi üretimde ilk ve en iyi uygulayan TOYOTA olup, daha sonra bu yaklaşım pek çok firma tarafindan benimsenmiş ve hizmet sektöründe de kullanılmaya başlanmıştır. Özellikle de 2000 'li yıllardan sonra hizmet sektöründe payı büyüyen sağllk sektöründe yalin düşünce teknikleri Lean Hospital (Yalın Hastaneler) adiyla uygulanmaya başlanmıştır. Bu çalışmada yalın düşünce sistemi, gelişimi, sağllk sektöründeki uygulamaları ve yalın düşünce uygulamaları gerçekleştirilen hastanelerde elde edilen iyileştirmeler hakkında bilgiler sunulmaktadır.

Anahtar Kelimeler: Değer akış haritalama; İsraf; İşlem; Sağllk sektörü; Yalın hizmet sistemleri.

\begin{abstract}
In the global world, competition is always increasing.The companies which want to continue their business have to use their resources effectively as much as possible. Both in production and in a service industry customer request and diversity is always increasing, and this causes complexity. There are so many different approaches and also methods are improved to solve this complexity. The most valuable method to solve this complexity is surely lean philosophy. TOYOTA is the company which implements this philosophy first and best. After a while this philosophy is adopted by so many different companies and it is started to use with service industry. Especially after the year 2000, in health sector, which is the growing branch of service industry started to use lean philosophy with the name of Lean Hospital. In this article, you will find lean idea system development procedure, applications in health sector and additionally the benefits of the lean philosophy in used hospitals.
\end{abstract}

Keywords: Healthsector; Lean service systems; Operation; Waste; Vale flowmapping

Makale Geliş / Received: 21.08.2020

Makale Kabul / Accepted:22.01.2021

${ }^{1}$ Ondokuz Mayıs Üniversitesi Akıllı Sistemler Mühendisliği, ORCİD:0000-0003-2557-6199, e-posta: nezirezeynep@ gmail.com,

${ }^{2}$ Ondokuz Mayıs Üniversitesi Endüstri Mühendisliği Bölümü, ORCİD:0000-0002-2493-6781, e-posta : fatih.yapici@omu.edu.tr

${ }^{3}$ Ondokuz Mayıs Üniversitesi Endüstri Mühendisliği Bölümü, ORCİD:0000-0001-5214-3394, e-posta : hasan.bas@ omu.edu.tr

${ }^{4}$ Ondokuz Mayıs Üniversitesi Endüstri Mühendisliği Bölümü, ORCİD: 0000-0001-5875-1446, e-posta :ahad.furugi@omu.edu.tr Sorumlu Yazar: Hasan BAȘ 


\section{GíRiş}

Dünyanın nüfuslanma süreci, insanın yerleşik hayata geçtiği Neolitik dönemle başlamış ve daha sonra yapılan teknolojik gelişmeler ile hem insanın ortalama ömrü uzamış, hem de nüfus artışı daha da hızlanmıştır. Artan nüfus ile birlikte hizmet sektöründe ciddi oranda büyüme yaşanmış, hizmet sektöründe görülen bu büyüme sağlık sektörüne de yansımış ve sağlık sektörü hizmet sektörleri arasındaki payını arttırmıştır (Aslan, 2003). Gelişen teknoloji, artan eğitim ve gelir düzeyi ile birlikte sağlık sektöründeki hizmet alan kişi sayısı artmış ve sistem daha karmaşık hale gelmiştir. Bu karmaşık sistemin verimliliğini artırmak için israflardan arındırılmış yeni sistem ve yaklaşımlara ihtiyaç duyulmuştur. Sağlık sektöründe, tıp bilimlerinin haricinde diğer bilimlerde eğitim görmüş kimseler de istihdam edilmeye başlamış ve disiplinler arası çalışmalar hız kazanmıştır. Özellikle mühendislik alanında birçok sektörde başarılı bir şekilde uygulanan birçok yöntem sağlık sektöründe de uygulanmaya başlanmıştır. Bunlardan en önemlileri; istatistiksel kalite kontrol yöntemleri, yalın düşünce, 6 sigma, veri zarflama, maliyet etkinlik analizi olarak sınıflandırılabilir. Kullanılan yeni yöntemler sayesinde sağlık sektöründeki mevcut kaynakların daha etkin bir şekilde değerlendirilme olanağı doğmuştur. Yalın düşünce, Taiichi Ohno ile Toyoda ailesinin katkılarıyla geliştirilmiş bir sistemdir. Yalın üretim; mümkün olan en az kaynakla, en kısa zamanda, en ucuz ve hatasız bir şekilde müşteri talebini tam anlamıyla karşılayabilecek bir üretim sistemidir (Lopez ve ark., 2013).

Sağlık işletmelerinde yalın düşünce ilkelerinin uygulanması; hastaların süreçler arasında daha az beklemesini, hastaların tedavilerine çok daha hızlı başlanılmasını, gereksiz analizlerin yapılmamasını, laboratuvar analiz sonuçlarının doktorlara çok daha hızlı ulaştırılmasını, bir gün içerisinde çok daha fazla sayıda hastanın tedavi görmesini ve bu şekilde maliyetlerin düşürülmesini sağlanmış olacaktır.

\section{YALIN DÜŞÜ̈NCE TANIMI VE TARİHSEL GELIŞ̧iMI}

Hızla değişen ve gelişen rekabet ortamında, işletmelerin ayakta kalabilmesi; mevcut kaynaklarını en etkin şekilde kullanmak suretiyle zaman ve iş gücü kaybının neden olduğu israf oluşturacak etkenleri ayıklayarak sağlanacaktır. Yalın üretim, üreticilere rekabet avantajı sağlamakla beraber değişen müşteri ihtiyaçlarını da etkin bir biçimde karşılamaktadır (Storch\&Lim, 1999).

İş yaşamındaki israflar, yerden tuğlaları alan duvar ustalarını izleyen hareket verimliliği uzmanı Frank Gilbreth tarafından fark edilmiştir. Duvar ustası $2,3 \mathrm{~kg}$ (5 pound) ağırlığındaki tuğlayı almak için bedeninin üst kısmını kaldırıp indirdiğini dolayısıyla, vücudunun fazla ağırlığa maruz kaldığını ve verimliliği önemli ölçüde azalttığını fark etmiştir. Performansı artırmak için tuğlaları insanların bel hizasına getiren iskeleler kurulmasıyla çalışanlar daha az efor sarf ederek, çalışma hızlarını üç kat artırmışlardır.

1900'lü yılların ilk başlarında Henry Ford'un otomobil üretimine başlaması, bu sektörün tüm dikkatleri üzerine çekmesini sağlamıştır. İkinci dünya savaşı boyunca askeri araç üretmek zorunda kalan Toyota Motor işletmesi, savaş sonrasında seri otomobil üretimine başlamak istemiş ve çalışmalarına Eiji Toyoda ve Taiichi Ohno önderliğinde başlamıştır.

1950 yılında incelemeler yapmak üzere Ford'un Detroit'teki zamanının en etkili imalat tesisi olan Rouge tesisine giden Eiji Toyoda isimli Japon mühendis tesisinin her noktasını detaylı olarak inceler. Eiji Toyoda Japonya'ya döndükten sonra; bir üretim dehası olan Taiichi Ohno ile birlikte, seri üretim sisteminin Japonya için uygun olmadığı sonucuna varırlar (Dennis, 2007). Daha sonra Toyota 1945'li yıllardan beri israfi elimine ederek mevcut kaynaklarla verimliliği artırmak için kendi sistemini oluşturmuştur. Geliştirilen bu sistem üretim sektörü dışında da birçok alanda da kullanılmaktadır. Yalın üretim / düşünce sistemi; bankacılık sektöründen hastanelere kadar birçok hizmet sektöründe uygulanmıştır ve uygulanmaya devam edilmektedir. Japonya'da diğer şirketlerce de kullanılan bu yaklaşım, Japon şirketlerini Dünyadaki diğer şirketlerden daha başarılı hale getirmiştir. Japon şirketleri uzun yıllar bu başarının nedenini gizleyebilmiş ancak 1991 yılında Womack ve Jones "Dünyayı Değiştiren Makine" adıyla yayınladıkları kitapla Toyota Üretim Sistemini tüm Dünya'ya tanıtmışlardır. (Mol \& Birkinshaw, 2008)

\section{SAĞLIK SEKTÖRÜNDE YALIN HIZMETLER}

Yalın düşünce ve uygulamaları ortaya çıkışından itibaren geliştirilerek bütün sektörlere yayılmış ve özellikle 2000 yılından sonra sağlık sektöründe maliyetlerin düşürülmesi, hasta memnuniyetinin arttırılması için uygulanmaya başlamıştır. Alquist \& Bosch (2008) Heinbuch (1995), Jacobs \& Palfrey (1995), Whitson (1997) sağlık işletmelerinde yalın düşünce sisteminin ilkeleri ilk kullanan isimler olarak karşımıza çıkmaktadır(Yıldız, 2015). Ülkemizde de bu konuda yapılan çalışmalar yetersiz olmakla birlikte, son zamanlarda ihtiyaç ve ilgi duyulan alanlardan biri haline gelmiştir. Tablo 1'de son 12 yıl içerisinde ülkemizdeki insanların ortalama yaşı, sağlık kuruluşlarına başvuru sayısı, hastane ve hasta yatak sayılarına ilişkin verilen görülmektedir (Sağlık Bakanlı̆̆ İstatistiki veriler, 2015). 
Tablo 1. Nüfus, hasta, sağlık kurulușu ve çalışanlarına ait bilgiler

\begin{tabular}{|c|c|c|c|}
\hline \multicolumn{2}{|c|}{ Nüfus, hasta, sağlık kuruluşu ve çalışanlarına ait bilgiler } & 2002 & 2014 \\
\hline \multirow{2}{*}{$\begin{array}{l}\text { Yaşam süresine } \\
\text { bilgiler }\end{array}$} & 65 yaş ve üzeri nüfus oranı $(\%)$ & 4 & 8 \\
\hline & Beklenen Yaşam süresi (Yil) & 73.1 & 77 \\
\hline \multirow{4}{*}{$\begin{array}{l}\text { Hastane, yatak, doktor } \\
\text { ve hemşire sayılarına ait } \\
\text { bilgiler }\end{array}$} & Hastane Sayıları (Adet) & 1156 & 1528 \\
\hline & Yatak Sayıs1 (Adet) & 160.000 & 206.836 \\
\hline & Toplam Hekim Sayısı (Adet) & 57.406 & 77.876 \\
\hline & Hemşire Sayısı (Adet) & 57.360 & 94.404 \\
\hline \multirow{5}{*}{$\begin{array}{l}\text { Sağlık kuruluşu başvuru, } \\
\text { ameliyat sayılarına } \\
\text { ilişkin bilgiler }\end{array}$} & Birinci Basamak Başvurusu (milyon) & 60 & 219 \\
\hline & Hastane başvurusu (milyon) & 125 & 649 \\
\hline & Kişi başı sağlık kuruluşu başvuru sayısı (XX) & 1.9 & 5.1 \\
\hline & Yatan hasta sayısı (milyon) & 5.5 & 13 \\
\hline & Ameliyat sayıs1 (milyon) & 1.6 & 4.8 \\
\hline
\end{tabular}

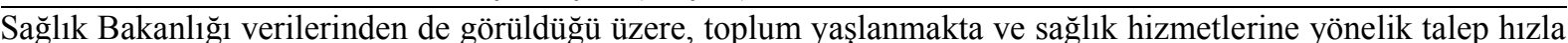
artaktadır. Sağlık sektörü kaynaklarındaki artışın talep oranındaki artışı karşılamadığı görülmektedir. Son on yılda hasta sayıs1 \% 310, yatan hasta sayıs1 \%237 artarken hastane sayıs1 \% 32, yatak sayıs ise ancak \% 29 artmıştır. Sağlık hizmetlerine talep hızla artarken, sağlık sektörünün içeriği kapsayan; hastane sayıları, yatak sayısı, hekim sayısı, hemşire sayılarının aynı oranda artmadığı görülmektedir. Sağlık sektöründeki talebin, mevcut durumlarla en iyi ne şekilde cevap verilebileceğinin yolları araştırılmaktadır. Kaynakları verimli şekilde kullanıp, israfı elimine etmekle verimliliği artırma odaklı olan yalın düşünce yaklaşımları sağlık alanında artarak kullanılmaktadır. Yalın ilkelerin her kurumda uygulanabilirliği yapılan çalışmalarda görülmektedir. Sağlık sektöründe yalın düşünce sistemini kullanmak; olası darboğazları bulup çözmede, gereksiz işlem ve değer katmayan bekleme sürelerinin elimine edilmesinde, yapılan işlemleri daha da kolaylaştırarak mevcut kaynakların daha etkin bir şekilde kullanımında değerlendirilmesi mümkün olacaktır. Yalın düşüncenin birincil temel ilgi odağı israfları önlemek olup Tablo 2' de sağlık sektöründe gerçekleştirilen işlemlerde oluşması muhtemel olan ve dikkate alınması gereken 7 israf verilmektedir (Correa ve ark., 2005).

Tablo 2. İmalat ve sağlık sektöründe 7 israfın karşılaştırılması

\begin{tabular}{|c|c|c|}
\hline İsraf türü & Açıklama & Sağlık Sektörü \\
\hline $\begin{array}{l}\text { Fazla } \\
\text { üretim }\end{array}$ & $\begin{array}{l}\text { Müşterinin } \\
\text { ihtiyacından } \\
\text { Fazla üretmek }\end{array}$ & $\begin{array}{l}\text { Personel çizelgesini ayarlamak için zamanı gelmeden önce verilen haplar } \\
\text { (ilaçlar). Laboratuvar çizelgesini ayarlamak için zamanı gelmeden önce yapılan } \\
\text { testler. } \\
\text { Hastane personelinin ya da ekipmanın is yükünü dengelemek için yapılan } \\
\text { tedaviler }\end{array}$ \\
\hline Taşıma & $\begin{array}{l}\text { Değer katmayan } \\
\text { ürünün hareketi }\end{array}$ & $\begin{array}{l}\text { Hareket eden örnekler. Hareket eden numuneler. } \\
\text { Test (muayene) için hareket eden hastalar. Tedavi için hareket eden hastalar. }\end{array}$ \\
\hline Hareket & $\begin{array}{l}\text { Değer katmayan } \\
\text { insan hareketi }\end{array}$ & $\begin{array}{l}\text { Hasta, doktor, dokümantasyon, malzeme, ekipman vb. aramak } \\
\text { Alet, malzeme, vb. toplamak. Evraklarla uğraşmak }\end{array}$ \\
\hline Bekleme & $\begin{array}{l}\text { Malzeme, bilgi, } \\
\text { insanlar ya da } \\
\text { ekipman hazır } \\
\text { olmadığında ortaya } \\
\text { çıkan bos zaman }\end{array}$ & $\begin{array}{l}\text { Yatış işlemleri. Acil Servise kayıt işlemleri, muayene ve tedavi, taburculuk } \\
\text { işlemleri, laboratuvar test sonuçlarında yaşanan gecikmelerden dolayı bekleyen } \\
\text { hastalar }\end{array}$ \\
\hline $\begin{array}{l}\text { Gereksiz } \\
\text { işlem }\end{array}$ & $\begin{array}{l}\text { Müşteri bakış açısıyla } \\
\text { Bakıldığında değer } \\
\text { yaratmayan çaba }\end{array}$ & $\begin{array}{l}\text { Yeniden muayene. Aşırı dokümantasyon. Gereksiz prosedürler. } \\
\text { Fazla sayıda yatak hareketi. Fazla sayıda muayene }\end{array}$ \\
\hline Stok & $\begin{array}{l}\text { Elde, müşterinin tam } \\
\text { olarak istediğinden } \\
\text { daha } \\
\text { fazla malzeme, parça } \\
\text { ya da ürün olması }\end{array}$ & $\begin{array}{l}\text { Tahsis edilen yataklar. Ecza stoku } \\
\text { Laboratuvar malzemesi. Analiz için bekleyen numuneler. Yatan hastalar }\end{array}$ \\
\hline Hatalar & $\begin{array}{l}\text { Hata, yeniden işlem } \\
\text { ya da eksik içeren } \\
\text { işler Müşterinin (bir } \\
\text { sonraki prosesin), } \\
\text { talep ettiğinden daha } \\
\text { düşük iş } \\
\text { yapmak }\end{array}$ & $\begin{array}{l}\text { Tedavi hatası. } \\
\text { Yanlış hasta } \\
\text { Yanlış prosedür. Eksik bilgi } \\
\text { Yetersiz klinik sonuçları } \\
\text { Yeniden düzenlemeler }\end{array}$ \\
\hline
\end{tabular}




\subsection{Sağlık sektöründe gerçekleștirilmiş bazı yalın felsefe uygulamaları}

Yalın düşünce ile yapılan tıbbi yayınlar (yalın düşünce, yalın süreç, yalın yönetim, yalın 6 siğma) ve yıllara göre değișen sayıları hakkında bilgi edinmek üzere sadece Pub-Med veri tabanında indekslenen makale sayılarındaki değişim Tablo 3'de gösterilmiştir (Pubmed, 2016).

Tablo 3. Yalın düşünce ile ilgili Pub-med 'de indekslenen bilimsel makaleler

\begin{tabular}{lcccc}
\hline Yillar & $\begin{array}{c}\text { Yalın Süreç } \\
\text { (Adet) }\end{array}$ & $\begin{array}{c}\text { Yalın yönetim } \\
\text { (Adet) }\end{array}$ & $\begin{array}{c}\text { Yalın Altı Sigma } \\
\text { (Adet) }\end{array}$ & $\begin{array}{c}\text { Yalın metodoloji } \\
\text { (Adet) }\end{array}$ \\
\hline 1995 & 13 & 15 & 715 & 107 \\
2000 & 17 & 43 & 899 & 236 \\
2005 & 40 & 59 & 1128 & 396 \\
2010 & 95 & 137 & 1206 & 672 \\
2015 & 133 & 205 & 1950 & 1037 \\
\hline
\end{tabular}

Son zamanlarda, birçok bilim insanının araştırma konularından biri sağlık sektöründe yalın felsefe uygulamalarıdır. Tıpta Yalın düşünce uygulamalarının artan önemi Tablo 3'den de anlaşılmaktadır.

Virgina Mason Medical Center'de çeşitli yalın düşünce (Değer Akışı Haritalama, 5S, İş Akıș Haritalama) uygulamalarında bulunularak, bekleme süresi $\% 14$ azalmış ve tedavi edilen hasta sayısında $\% 57$ artışın sağlandığı belirtilmiștir (Black \& Miller, 2008)

Pittsburgh'taki Allegheny General Hospital hastanesi de yalın üretim metotlarını uygulayan hastanelerden biridir. Burada üzerine en çok düşülen alan, yoğun bakım ünitesidir. Toyota üretim tekniklerinden etkilenen hastanede yoğun bakımda çalışan herkese yetki verilmiştir. Toyota montaj hattında, her çalş̧ana bir sorunla karşılaşıldığında butonu çekip hattı durdurma yetkisi verilmiştir. Pittsburgh'taki Allegheny General Hospital da yoğun bakım ünitesinde tüm çalışanlara, herhangi bir sorunla karşılaşıldığında diğer bölümlerin sorumlularına ulaşma yetkisi verilmiştir. Yöneticilerine göre bu yöntemler çözüme ulaşmayan bir şey kalmamaktadır (Lummus ve ark., 2006a)

Missoula Medikal Kliniği’nde bir ortopedist ve bir hasta bakıcı yalın düşünce uygulamalarıyla bakılan hasta sayısının artırılması yönünde araştırmalarda bulunmuş, tüm prosesler gözlenmiş ve darboğazın ameliyathane kaynaklı değil, hastaların ayrılma ve toparlanma alanında olduğu tespit edilmiştir. Bu alanda bekleme süresi 90 dakika olmuş, bu da diğer hastanın bu alana girmesi için en az bekleyeceği süre olarak belirlenmiştir. Yapılan uygulamalarla çevrim süresi 90 dakikadan 60 dakikaya düşürülmüştür. Böylelikle iyileştirme öncesi hizmet verilen hasta sayısı 4 'ten 5 'e yükseltilerek, $\% 25^{\prime}$ 'lik bir iyileştirme sağlanmıştır (Lummus ve ark.,2006b) .

Michigan Üniversitesi Radyasyon Onkoloji anabilim dalı, beyin ve kemik kanseri ile gelen hastaların tedavi edilme süreçlerinde yalın düşünce uygulamalarından faydalanmış ve yapılan çalışmada, darboğazın, tıbbi belgelerin düzenlenmesiyle alakalı olduğu tespit edilmiştir. Gelecek durum haritalarının kullanılmasıyla ortalama 290 dakika olan süreç 225 dakikaya, 27 ayrı aşamada gerçekleştirilen süreç ise 16'ya ve bekleme süresi yaklaşık 1 güne indirilmiş̧ir. Hastaların \%94'ü daha önce bir günde tamamlanmayan süreçleri bir gelişlerinde tamamlayabiliyor hale gelmiştir (Kim ve ark.,2007)

Pearce (2004), hastaların taburcu olma sürecine odaklanmış ve bu alanda iyileştirme yapmak istemiştir. Hastaların yaklaşık \%80'inin taburcu edildikten sonra evlerine gittiğini, basit kontrol ve tedavi ihtiyacı olan hastalar olduğunu, bu süreçler üstünde yalın düşünce uygulamalarından faydalanılarak, hasta akış ve yatış sürelerini verimli kullanma konusundaiyileşme yapılabileceğini savunmuştur.

Fillingham'a (2007)göre, Bostın Hospital hastanesinin travma bölümünde hastalar, yöneticiler, terapistler, hemşireler ve doktorlardan oluşan takım hasta faaliyetlerini haritalandırarak katma değer oluşturmayan tekrarlanan işlemleri ve hataların olduğunu tespit etmişlerdir. Kullandıkları Değer Akış Haritalama (DAH) tekniği ile düşük kalitede hizmet verdikleri sonucuna ulaşmışlardır. Yapılan 9 aylık süre içinde işleri standartlaştırılması, gerekli malzemelerin yerlerinin belirlenmesi gibi bir dizi iyileştirmeler yapmışlardır. Sonuçta hastaların süreçte kalma zamanlarında $\% 33$ ve evrak işleri zamanında ise $\% 42$ lik bir azalmanın sağlandığını rapor etmişlerdir.

Salt Lake City şehrinde faaliyet gösteren Intermountain Health Care (IHC), 2002'de sürekli iyileştirme amaçlı, yalın düşünce metotlarını test etmek için pilot uygulama başlatmışlardır. Uygulanan metotlarla ön büro çalışanlarının zaman israflarında önemli ölçüde azalma görülmüştür. Anatomik patoloji laboratuvarındaki patolog raporlarının çevrim zamanını beş günden iki güne indirildiğini tespit etmişlerdir (Jimmerson ve ark.,2005).

Avustralya'da bulunan "Flinders Medical Centre Adelaide" hastanesinde yapılan çalışmada, acil servis bölümünde hastalar; muayene olup taburcu olanlar ve başka tetkiklere de ihtiyacı olan hastalar olmak üzere ikiye ayrılmıştır. Bu uygulama sonucunda bekleme süresinde $\% 25$ 'lik bir iyileşmenin sağlandığını ifade etmişlerdir (Jones \& Mitchell, 2006). 
Amerika'da "Shouldice Hospital" de hastalar ameliyat sonrasında, kendisi için hazırlanmış tekerlekli sandalyelere doktorların yardımıyla taşınmıştır. Geliştirilen bu iki yönlü iletişim sayesinde hastalar sürece dahil olmayı öğrenmiş ve daha hızlı taburcu olmuşlardır, böylelikle hastane maliyeti minimize edilmeye çalışılmıştır (Bowen \& Youngdahl, 1998).

Patterson (2006); "Virginia Mason Medical Center" hastanesinde TÜS’ü (Toyota Üretim Sistemi) sağlık sistemine entegre ederek VMÜS'ü (Virginia Mason Üretim Sistemi) oluşturmuştur. Oluşturulan bu sistemin en büyük amacı işlemleri ilk seferde doğru olarak gerçekleştirmektir. Bu amaç için JIT ve JIDOKO tekniklerinden faydalanılmaktadır. Jidoko bir anormallik tespit edildiğinde sistemin durdurulma yetkisinin tüm çalışanlara verilmesidir. Hastanelerde 'de, hasta için güvenlik alarm sistemi kurularak yanlış bir müdahalenin hemen durdurulması istenilmiştir.

Mathur ve arkadaşları, Covenant Sağlık Sisteminde hastaların sistemde kalış sürelerinin uzunluğunu ele almışlardır. Hasta memnuniyeti ile sistemde geçirilen süre arasında ters orantılı bir bağ vardır. Sistemde geçirilen süreyi azaltarak, hasta memnuniyetini artırmaya yönelik yalın düşünce ve 6 sigmadan faydalanılabileceğini ifade etmişlerdir (Mathur \& ark., 2006).

Farklı bölgelerde 1600 'den fazla çalışana sahip ve çok yönlü sağlık hizmeti veren bir grup olan Progressive Healthcare yalın üretim prensiplerini uygulayan farklı bir örnek olarak karsımıza çıkmaktadır. Bu sağlık kurulusunun gerçekleştirmek istediği değer akışının kapsamı bir hastanın birinci basamaktan sağlık hizmeti almak için yaptığı randevu talebinden, sağlı hizmeti için geldiği ve hastaneyi terk ettiği zamana kadar olan bölümü kapsamaktadır. Hastane yöneticileri israfı elimine etmeye ve bir hasta bakış açısıyla bakıldığında nelerin değer oluşturduğu düşüncesi ile prosesleri değerlendirmeye karar vermişlerdir. Yalın eğitimler sayesinde personel operasyonları standardize ve işyerini organize edebilmiş, iş akışı da iyileştiği gözlemlenmiştir (Bushell ve ark., 2002).

Efe ve arkadaşları bir "Numune ve Eğitim Araştırma Hastanesinin Acil Servis" bölümünde yalın düşünce sistemini uygulamışlardır. Yaptıkları çalışmada darboğaz olarak "kan tahlil sonucu beklemeyi" bulmuşlardır. Kan veren hastaya tahlil sonuçlarının çıkması 60 dakika civarında olsa da 30 dakikalık güvenlik vakti eklenerek söylenmektedir ki bu bir israftır. Ayrıca, çıkan sonuçlar doktor tarafından iki kez onaylandıktan sonra sisteme girilmektedir, bu da bir muda (israf) dır. Yapılan çalışmada belirlenen israflar elimine edildikten sonra 132, 5 dakikalık kan tahlili çevrim süresi $\% 36,6^{\prime}$ 'lk bir iyileşme ile 84 dakikaya indirildiği ifade edilmektedir (Efe ve ark., 2011).

Doğan ve arkadaşları bir devlet hastanesinin "fizik ve rehabilitasyon" bölümünde, değer akış haritalama yöntemini kullanarak, yalın düşünce uygulamasını gerçekleştirmişler ve sonuçta; EMG çekimi öncesi bekleme süresini 3 günden 1 güne, MRG çekimi öncesi bekleme süresini 2 günden 1 güne, MRG çekim sonucunun çıkmasını bekleme süresini 2 günden 1 güne, Doppler USG çekimi öncesi bekleme süresini 4 günden 1 güne indirmişlerdir. Ayrıca yine aynı çalışmada KMD çekim sonucunun çıkmasını bekleme süresi 1 gün olarak, Ultrason çekimi öncesi bekleme süresi 1 gün olarak, BT çekim sonucunun çıkmasını bekleme 1 gün olarak aynı kaldığı ifade edilmiştir (Doğan ve ark., 2011).

Bir özel hastanede yapılan yalın düşünce uygulamaları kapsamında değer akış haritalama (DAH) yöntemi kullanılmış, bu kapsamda yeni yerleşim planı uygulanarak bölümler arası mesafe azaltılarak çevrim süresinde iyileştirmeler yapılarak hastalar için katma değeri olan süreyi 108,5 dakikadan 91 dakikaya düşürmüşlerdir. Ayrıca laboratuvarda uygulanan $5 \mathrm{~S}$ teknikleri sayesinde tahlil ve tetkik sonuçlarının daha kısa sürede çıkmasını sağlamıştır (Aytaç, 2009).

Shannon ve arkadaşları; yalın üretim sistemlerinde uygulanan süreç iyileştirme yöntemleri ile hastanelerdeki enfeksiyon sorunlarını yok edilip edilmeyeceği üzerine araştırma yapmışlardır. Montana General Hospital'da hasta bakımını kusursuzlaştırma adını verdikleri bu yöntemi beş aşamalı olarak uygulamışlardır. Beş aşamayı şu şekilde gerçekleştirmişlerdir;

- Mevcut olan sorunların doğru olarak tanımlanması ve hatanın sıfira indirilerek hesaplanması

- Yapılan işlerin standartlaştırılması ve stabil olması için inceleme yapılması

- Elde edilen verilerin hemen değerlendirilmesi ve semptomik her hasta üzerinde uygulanması

- Sorunların oluştuğu zaman hemen çözülmesi

- Süreç iyileştirmeyle ilgili sürekli eğitimin verilmesi

Gerçekleştirdikleri bu uygulamalar sayesinde enfeksiyon kapan hastalarda \%90 oranında iyileşmenin olduğunu rapor etmişlerdir (Shannon ve ark., 2006)

Nebraska'daki Alegent Health Hastanesinde yalın düşünce uygulamalarıyla yeni alet ve personel eklenmeden, laboratuvar işlemlerinde çevrim süresi \%60 kısaltılmıştır. Wisnonsin'de The Care Hastanesinde ortopedik cerrahide hasta bekleme süresi 14 haftadan 31 saate düşürülmüștür. Minnesota'daki Park Nicollet Health Services'de yalın düşünce uygulamaları gerçekleştirilerek 7,5 milyon dolarlık tasarruf sağlandığı tespit edilmiştir (Graban, 2008) 


\section{SONUÇ VE ÖNERILLER}

Hastaneler gibi sağlık kuruluşları sağlık sektöründe hizmet üreten işletmelerdir. Toplumdaki yaşlılık oranı giderek artmaktadır, bundan dolayı da sağlık hizmetlerine olan ihtiyaç artmış ve daha da artacağı aşikârdır. Sağlık sistemlerindeki finansal koşullar gerektiği hızla iyileşememekte ve mevcut durumdaki kaynaklarla artan talebi karşılamak pek mümkün durmamaktadır. Dengeyi sağlayacak bir sisteme ihtiyaç duyulmaktadır. Yalın düşünce uygulamaları, hastane işlemlerinde önemli ölçüde iyileştirmeler yapma kapasitesine sahiptir. $\mathrm{Bu}$ yaklaşımla mevcut kaynaklar en etkin şekilde kullanmak suretiyle katma değeri olmayan işlemler azaltarak, israflar yok edilerek, hasta akış süreçlerinde iyileşme, bekleme sürelerinde azalma, tanı ve tedavi süresinde kısalma, tedavi edilen hasta sayısında iyileşmeler ve çalışan kişilerin moralinde artışlar sağlanabilir.

Ülkemizde işletmeler yeni bir sisteme geçiş yapmaktan genelde sakınmakta ve yeni sistemin maliyet artıracağı düşünülmektedir. Bu konuda yapılan çalışmaların artması sağlık sektöründe bir farkındalık oluşturacaktır. Yalın düşünce uygulamalarını gerçekleştiren işletme sayısı arttıkça, diğer işletmeler içinde teşvik edici bir unsur olacağı düşünülmektedir.

\section{ÇIKAR ÇATIŞMASI}

Yazarlar arasında çıkar çatışması bulunmamaktadır. Finansal destekte bulunan kişi yada kuruluş yoktur.

\section{YAZAR KATKISI}

Nezire Zeynep Taşdemir: Fikir ve yazım aşamasında

Fatih Yapıcı: Fikir ve yazım aşamasında

Hasan Baş: Yazım aşamasında

Ahad Furugi: Yazım aşamasında

\section{KAYNAKLAR}

Alquist, M. ve Bosch, J. P. (2008). Treatment Mapping: A Systematic Methodology to Assess Quality, Efficiency and Variability in the Hemodialysis Delivery Process. Blood Purification, 26, 417-422.

Aslan, Şebnem, (2003). Hastane İşletmelerinde Örgütsel Çatışma: Teori ve Örnek Bir Uygulama. DoktoraTezi, Selçuk Üniversitesi Sosyal Bilimler Enstitüsü, Konya.

Aytaç, Z. (2009). Hastanelerde yalın yönetim sistemleri. Yüksek Lisans Tezi, İstanbul Teknik Üniversitesi Fen Bilimleri Enstitüsü, İstanbul.

Black, J. R.\& Miller, D. (2008). Toyota Way to Healthcare Excellence: Increase Efficiency and Improve Quality with Lean, Health Administration Press, Chicago,

Bowen, D. E. \& Youngdahl, W. E. (1998).Lean service: in defense of a product online Approach, International Journal of Service Industry Management, 9(3), 207- 225

Bushell, S., Mobley, J. \& Sheles B., (2002). Discovering Lean Thinking at Progressive Healthcare. Journal for Quality and Participation, 25(2), 20-25.

Correa, F. A., Gil, M. J. A. \& Redib L. B.(2005). Benefits of Connecting RFID andLean Principles in Health Care.Working Paper 05-44, Business Economics, Series, 10, 1-13.

Dennis, P. (2007). Lean Production Simplified: A Plain-Language Guide tothe World's Most Powerful Production System (2nd edition). New York: Productivity Press.

Doğan N.,(2011). Sağlık sektöründe etkinliğin iyileştirilmesi: Bir yalın üretim uygulaması, Doktora tezi, Erciyes üniversitesi, Kayseri.

Efe, Ö. F. (2009). Hizmet isletmelerinde Yalın Üretim ve Yönetim Felsefesi, Yüksek Lisans Tez Semineri, Selçuk Üniversitesi Fen Bilimleri Enstitüsü, Konya.

Fillingham, D. (2007). Can Leansavelives Leadership in Health Services, 20(4), 231-241

Graban, M. (2008).Yalın Hastane, Optimist Yayınevi, İstanbul.

Grove A.L., Meredith J.O., MacIntyre M., Angelis J. \& Neailey K., (2010). UK Health Visiting: Challenges Faced During Lean Implementation, Leadership in Health Services, 23, 3

Jimmerson, C., Weberand, D. \& Sobek D. K. (2005). Reducing Waste and Errors: Piloting Lean Principles at Intermountain Healthcare, Joint Commission Journal on Quality and Patient Safety, 31 (5), 249-25

Jones, D. ve Mitchell, A., (2006). Lean Thinking for the NHS, Lean Enterprise Academy, UK.

Kim C.S., Hayman J.A., Billi J.E., Lash K.\& Lawrance T.S. (2007). The Application of Lean Thinking to the Care of Patients with Bone and Brain Metastasis with Radiation Therapy, Journal of Oncology Practice, 3,4

Lopez, A., Santos, J. F. \& Arbos, L. C.(2013). Lean Manufacturing: Costing the Value Stream, Industrial Management and Data Systems, (113), 5, 647-668. 
Lummus R. R., Vokurkaand, R. J. \& Rodeghiero,B. (2006). Improving Quality through Value Stream Mapping: A Case Study of a Physician's Clinic. Total Quality Management, 17 (8), 1063-1075.

Mathur, D.S., Stone, D., Simpson, D. \& Barnt, W. (2006). Bridging Lean Six Sigmato Engineering Management Model Through Healthcare. International Journal for Quality in Healthcare, 14, 493-502.

Mol, M. J. ve Birkinshaw, J. (2008). Giant Steps in Management. Prentice Hall, UK.

Patterson, S., (2006). Seeking Perfection in Healthcare: Applying the TPS to Medicine, Virginia Mason Medical Center Final Report.

Pearce, J. (2004). Achieving Timely 'Simple' Discharge From Hospital - A Toolkit forthe Multi-diciplinary Team, Department of Health Chlorine Free Paper, London.

Pubmed indekslenen makale sayıs1.(2016).www.pupmed.com Son erişim tarihi 01.01.2016

Sağlık Bakanlığı.(2016).http://www.saglik.gov.tr/TR/belge/1-2952/istatistik-yilliklari.html Son erișimtarihi: $\underline{02.01 .2016}$

Shannon, R. P.,Frndak, D. ve Cummins, D., (2006). Using Real-Time Problem Solvingto Eliminate Central LineInfections. Journal on Qualityand PatientSafety, Vol: 32, No: 9, pp. 479- 487.

Storch, R. L. \& Lim, S. (1999). Improving Flow to Achieve Lean Manufacturing in Ship building. Production Planning and Control, 10 (2), 127-137.

Yıldız S. (2015). Sağlık işletmelerinde yalın uygulamalar üzerine genel bir literatür taraması. Uluslararası Sağlık Yönetimi Ve Stratejileri Araştırma Dergisi, 1:1 